\title{
Current state of analytical chemistry teaching in Russian universities
}

\author{
Tatiana Shekhovtsova ${ }^{1}$
}

Published online: 8 May 2018

(C) Springer-Verlag GmbH Germany, part of Springer Nature 2018

\section{Introduction}

The last decade has been a very important and hard time for Russian higher education as it had to be significantly reformed. Because of the decision of the Russian Ministry of Higher Education and Science to join the Bologna Process, which was implemented in 1999, from 2011 Russian universities should have changed from their traditional system of teaching ( 5 years training specialists) and begun to work according to the new standards and programs. It should be explained what the term "specialist" means in Russia. In 2012 the Russian Federation law "On Education in the Russian Federation" implemented three levels of higher education, which correspond to the sixth, seventh, and eighth levels of the European Qualifications Framework (https://ec.europa.eu/ ploteus/en/content/descriptors-page, http://ec.europa.eu/ education/lifelong-learning-policy/doc44_en.htm). Both specialist and master qualifications are included in the seventh qualification level as they both fully meet its criteria of knowledge, skills, and competences. Comparisons of the specialist program also exist in Europe: they are the integrative professional master program or special professional programs.

Most Russian universities had to introduce the three-cycle system: bachelor degree/master degree/Ph.D. degree. According to the framework for qualifications in the European Higher Education Area, bachelor graduates should have the ability to gather and interpret relevant scientific data; master graduates should have the ability to apply their knowledge and understanding in new or unfamiliar environments; and Ph.D. graduates should be capable of critical analysis, evaluation, and synthesis of new and complex ideas [1]. However, realizing the obvious drawbacks of training

Tatiana Shekhovtsova tnshekh@yandex.ru

1 Analytical Chemistry Division, Chemistry Department, M.V. Lomonosov Moscow State University, Leninskie Gory, 1-3, Moscow 119991, Russia bachelors and masters instead of specialists, many universities in the largest regions of Russia (in particular the universities of Archangelsk, Ufa, Chelyabinsk, Ekaterinburg, Kazan, Nizhniy Novgorod, Voronezh, and Samara) declared the coexistence of two educational systems: the two-tier bachelor and master system $(4+2$ years $)$ and the traditional system for "specialist" training according to the direction "fundamental and applied chemistry" (5 years). The third stage of education is a Ph.D. course (doctorate) lasting 4 years. The overwhelming majority of the more than 80 state universities in Russia (mostly technical) providing education in chemistry offer bachelor degrees. About 30 classical universities (where engineering disciplines are not taught) and several technical universities (e.g., the universities of Lipetsk, Voronezh, and Ekaterinburg) continue to offer a program for "specialists" in fundamental and applied chemistry; about $35 \%$ of them are simultaneously bachelor courses. About $30 \%$ of classical universities offer only bachelor courses, and approximately $30 \%$ of classical universities have master programs. Forty-seven classical universities are members of the Association of Classical Universities of Russia (http://acur. msu.ru/members_list.php); 26 of them are members of the Association of Leading Universities of Russia (http://alu. spbu.ru/english).

M.V. Lomonosov Moscow State University (MSU), the leading Russian university, and the chemistry department in particular were allowed to continue educating chemistry specialists only. However, it was decided that "specialists" at MSU would study for as long as 6 years. At the same time, the chemistry department of MSU also has programs and licenses for bachelor and master courses, and every year students from different universities in Russia and other countries attend bachelor and master courses.

The coexistence of two educational systems preserves the Russian traditional, well-established, and successfully tested system for training specialists for 5 years and provides education of the required quantity of qualified specialists for different regions. Besides, this approach gives young people the possibility to select the duration $(4,5$, or 6 years) and level of their education according to their wishes and financial and 
family situation, and it does not defy the principle of a European two-tier education system in universities.

\section{Undergraduate analytical chemistry course}

Entrants to those universities that offer both specialist and bachelor courses can select one of those two forms of study. In such cases, specialist students and bachelor students are taught separately, but usually according to almost identical programs during the first 3 years. To increase transparency and comparability of degree qualifications in different universities, all the programs of the main compulsory fundamental disciplines are virtually the same: they contain the same tasks in terms of students' knowledge, skills, and experience, and the same competences.

The order of the main compulsory fundamental disciplines in different universities is usually as follows: inorganic chemistry (first year), analytical chemistry (second year), physical chemistry (third year), and organic chemistry (fourth year). Students at the universities have to follow an obligatory curriculum, a definite order of fundamental disciplines, and they have no option to change this order or to miss any of the compulsory disciplines (in contrast to the rules of some universities in other countries [2]).

According to the recommendations of the Russian University Methodological Association, all classical universities should follow in their teaching process the same standardized program of analytical chemistry, which is matched with the requirements of modern analytical chemistry as a science, as well as an analytical service. The authors of the program derived from conventional ideas that students should learn the scientific fundamentals of analytical chemistry and analytical methods. Having learned the principles of this science, its general theory, and the mechanisms of physicochemical phenomena and processes, future specialists (and to a lesser extent future bachelors) should easily master new methods and instruments necessary for their work [3].

Since universities in different regions of the country differ in the quality of their equipment, in traditionally developed methods and fields of analytical chemistry, and in the time allocated for this discipline, it is natural that each department pays more or less attention to particular subdisciplines in teaching. The number of credits for such basic programs, and analytical chemistry in particular, differs depending on the university. The total study time for classes in the basic analytical chemistry course at classical universities corresponds to between 9 and 11 credits. Programs for bachelor students require $6-10$ credits.

In most Russian universities analytical chemistry is now taught in chemistry departments in the third and fourth terms. Usually there is one lecture (two academic hours), one seminar (two academic hours), and 8-10 academic hours of laboratory works per week. Analytical chemistry teaching during the third term includes several modules (Table 1).

The program for analytical chemistry in Russian universities described includes practically all topics and all aspects of analytical chemistry recommended by the European Chemistry Thematic Network (http://www.chemistry-eurolabels.eu/). Mainly, the modern trend consists in sufficiently decreasing the share of classical methods and increasing the share of instrumental methods of analysis, the metrological aspects, and computer-aided methods. Nonetheless, "wet chemistry" methods should still be included in basic analytical chemistry education [4, 5]. In 2013 only $40 \%$ of the universities paid more attention to training in instrumental methods (more than $50 \%$ of the allocated time), and in 2017 more that $75 \%$ of classical universities placed emphasis on such methods. In teaching instrumental methods, most of the universities allocate about the same time for spectroscopic and electrochemical methods. Unfortunately, less time is allocated for extremely popular and rapidly developing chromatographic methods. Such a situation is attributed to the lesser availability of corresponding equipment for universities for use in the teaching process.

Analytical chemistry is taught not only in chemistry departments but also in biology, geology, geography, medical, and soil and material sciences departments of classical universities. The same analytical chemistry divisions have to teach all students.

\section{Real-world sample analysis as the final work on chemical methods of analysis}

Traditionally for all universities, the autumn term of the second year is concluded with a qualitative and quantitative analysis of a real sample. The task is to analyze such a real-world sample with chemical methods (using both gravimetry and titrimetry) according to the procedures found by students themselves in the literature. Students should demonstrate their knowledge of theory, their ability to study the scientific literature, and the skills related to weighing, measuring volumes, and calculating masses and concentrations gained during the first term of studying analytical chemistry [6]. Students should present the results of their literature review and practical work in written form and answer orally appropriate questions with a detailed explanation of all stages of their experiment during the examination that finishes the first term and is devoted to chemical methods of analysis.

\section{Course research work using instrumental methods of analysis}

At the end of the basic analytical chemistry course at $75 \%$ of classical universities, students perform course research work 
Table 1 The themes of the lectures in the analytical chemistry course

\begin{tabular}{|c|c|}
\hline Module & Themes \\
\hline I & $\begin{array}{l}\text { Introduction to modern analytical chemistry; its position among other chemical disciplines. Types and stages of analysis. } \\
\text { General aspects of homogeneous equilibrium. } \\
\text { Acid-base equilibrium. Acid-base titration. } \\
\text { Formation, classification, characteristics, and application of complexes. Organic reagents; their application in analytical } \\
\text { chemistry. Complexometry. } \\
\text { Redox equilibrium. Redox titration }\end{array}$ \\
\hline II & $\begin{array}{l}\text { Heterogeneous equilibrium (solution-precipitate; aqueous-organic solutions). } \\
\text { Precipitate formation. Gravimetry. } \\
\text { Methods of separation. Precipitation. Extraction, separation and preconcentration techniques. } \\
\text { Theory and practice of sampling and sample pretreatment }\end{array}$ \\
\hline III & Quality assurance, method validation \\
\hline IV & $\begin{array}{l}\text { Spectroscopic methods of analysis (fundamentals and application of atomic emission and absorption spectroscopy, molecular } \\
\text { absorption spectroscopy, IR spectroscopy, molecular luminescence spectroscopy, and mass spectrometry) }\end{array}$ \\
\hline $\mathrm{V}$ & $\begin{array}{l}\text { Electrochemical methods (fundamentals and applications of potentiometry, voltammetry, coulometry, conductometry, } \\
\text { and electrogravimetry) }\end{array}$ \\
\hline VI & Chromatographic methods (fundamentals and application of gas chromatography and various types of liquid chromatography) \\
\hline
\end{tabular}

using instrumental methods of analysis. The time allocated for such research work differs substantially, corresponding to 1 or 2 credits. With regard to instrumental analysis, students at many universities can determine minor components of the alloys or residual elements of ores or minerals from the extracts stored in the first term. The choice of the appropriate instrumental analysis method as well as the analytes depends on the sample and preliminary information about its composition obtained during the first part of the research, fulfilled at the end of the third term by chemical methods. The final report is defended as part of the examination on analytical chemistry in the summer examination. Apart from their becoming familiar with the methods of analysis of common samples, the work with a real sample promotes students' interest in analytical chemistry and self-satisfaction with their efforts.

It is interesting to discuss the situation with the course work on analytical chemistry taking place at MSU. During the third term students have the possibility (as special excursions are organized) to visit all scientific laboratories of the Analytical Chemistry Division and to speak to the heads of and researchers in the laboratories. Students then select the laboratory and the theme for their small original scientific investigation (like a mini diploma work), which will use modern instrumental methods of analysis and be under the guidance of researchers or professors. Formally, a special period is scheduled for this research at the end of the fourth term ( 2 credits) in scientific laboratories (all lectures, seminars, and laboratory work have been completed by that time). Many students begin their research from the very beginning of the fourth term or even in the third term during their free time. After finishing this investigation, students have to present the results obtained in written form, including an appropriate literature review, experimental part, results, and discussion, and give an oral presentation in the presence of their whole student group, their tutors, and a commission of three professors. So, all students in the group (in total approximately 20 people) have the chance to learn more about the various types of research in different laboratories of the division and the application of modern methods of analysis. Some examples of recent topics for the course work are as follows:

- Separation of pharmaceutical enantiomers by highperformance liquid chromatography

- Determination of rocket fuel in water by gas chromatography-mass spectrometry with preconcentration by microextraction

- Analysis of oxide nanostructures by X-ray photoelectron spectroscopy

- Determination of sulfate ions using polyurethane foam modified with gold nanoparticles, stabilized by ions

- Detection of sepsis biomarkers in blood serum

- Creation of an electrochemical biosensor for continuous monitoring of lactate

- Solid-phase indicator systems for the determination of catecholamines and their metabolites studied by surfaceenhanced Raman spectroscopy

- Enzymatic determination of caffeic acid and epicatechin in plant raw material

- Quantum dots immobilized on silica gels as active component of a fluorescence sensor

Closer acquaintance with modern instrumental methods during the research work gives students a comprehensive idea of modern analytical chemistry [7], helps them enhance their knowledge, and helps them pass the examination on analytical chemistry with better results, and aids in recruiting students to the Analytical Chemistry Division for further specialization 
within it. Such activity is intended to engage students in all aspects of the process, from research work to experimental procedures, to collecting the required materials, doing the experiments, and analyzing, interpreting, and reporting the data [8]. This process increases students' understanding of fundamental concepts of modern methods of analysis, sampling, the purpose of standards, and instrument calibration.

\section{Module-rating system}

More than $80 \%$ of universities have designed and are using a module-rating system for evaluation of students' knowledge and the quality of their work. This means that practically all steps of a student's work during the whole yearcontrol works, colloquiums, laboratory works, home tasks (diagrams, titration curves, problem solving, etc.) - are controlled and graded with points. Depending on the final result for the year (the sum of points), a student will or will not pass the final examination: diligent students may get "excellent" or "good" marks "automatically" (without attending the oral examination); all other students have to pass an obligatory oral examination. Those who get "good" marks but would like to improve their results can also sit the oral examination and get the mark that they deserve. We consider this system to be very useful. It allows us to stimulate students to work more actively and systematically during the academic year (not just before the examinations), to improve the system for estimating education quality, and to conduct a knowledge check on analytical chemistry with the aid of a standard method.

\section{Majoring in analytical chemistry}

All Russian universities offer specialization in analytical chemistry during the fourth and fifth years for specialists (at MSU now during the fourth, fifth, and sixth years), or special "profiles" for bachelor students during the fourth year. When students are choosing a division for their major (usually at the end of the third year), chemistry department divisions compete with each other to obtain the best students for research. They organize "open door days" to show students their research laboratories with modern equipment and organize student scientific conferences to show modern trends in their field of chemistry, most interesting achievements, etc. Moreover, in this aspect the analytical chemistry divisions have great advantages in comparison with other divisions, as their professors can demonstrate excellent prospects for student participation in solving topical problems of chemical analysis in various areas of science and social life, and announce successful work of future analysts in the most powerful companies, analytical centers, and laboratories, etc. That is why many students (specialist and bachelor students) at different universities choose analytical chemistry as their major, as well as separate elective courses.

Russian universities have the right to independently select up to $70 \%$ of the educational programs for master and specialist special courses, both compulsory and (especially) elective. Every division can form its own set of academic disciplines, the order of their study, the number of teaching hours, and the ways to check students' knowledge. Of course, modern trends in chemistry, the level of and outlook for the development of analytical services in the country, the experience and traditions of the leading Russian and other universities, including European universities [9], the qualifications of the teachers, the availability of modern instrumentation, and the analytical methods that have been traditionally developed in each division are taken into consideration. Besides, the possibility of student transfer from one university to another and the necessity to have unified educational, methodological, and computer-based support is taken into account.

In general, the programs on analytical chemistry specialization for bachelor, specialist, and master students have different contents and durations. The time allocated for majoring in analytical chemistry at classical universities corresponds to between 6 and 12 credits for bachelor students and between 10 and 18 credits for specialist and master students.

The optimum way to better educate students consists in compiling the curriculum of an analytical chemistry major based on fundamental education, scientific research, and the formation of a set of skills and abilities necessary for practical work as an analytical chemist. The desired effect could be obtained if the student majoring in analytical chemistry is taught in an extra educational professional curriculum, aside from the conventional set of fundamental special courses. The extra educational professional curriculum is an interrelated set of optional special courses of an applied type intended for those who are going to work in particular areas of employment after graduating from the institution and who need appropriate knowledge. After the student has finished such an extra educational professional curriculum, a qualification may be conferred or a certificate may be given, which is coordinated with potential employers in the region and accepted when the employment is given. Participation in an extra educational professional curriculum should considerably increase the chances of a graduate getting a job in the sphere in which he or she is interested.

The block of disciplines for the analytical chemistry majors (specialists and masters) includes at least seven large unified special courses, which reflect the traditional approach to the specialization in classical universities. Great attention is paid to the discussion of problems 
connected with quality assurance in analytical chemistry [10]. The traditional set of special courses that are compulsory for all universities is as follows:

- Introduction to analytical chemistry (the place of analytical chemistry in the system of sciences, practical importance, system of methods, history, geography, basics of analytical services, and system of support: literature, instrumentation, etc.)

- Modern trends and applications of advanced spectroscopic methods of analysis (including atomic fluorometry, Xray spectroscopy, IR spectroscopy, and radiospectroscopy methods)

- Modern trends and applications of electrochemical methods of analysis (including bioelectrocatalysis and biosensors)

- Modern trends and applications of chromatographic methods of analysis (including supercritical fluid chromatography and capillary electrophoresis)

- Modern methods of separation and preconcentration (extraction, supercritical fluid extraction, sorption, distillation, membrane methods of separation, etc)

- Analysis of real-world samples (including industrial, technological, agricultural, forensic, environmental, and biological samples; theory of sampling and general problems of sample preparation).

- Fundamentals of quality assurance in analytical chemistry (structure, functions, and problems of development, standardization of analytical procedures, material certification, the certification of laboratories and management of their activities).

Special lecture courses on spectroscopic, electrochemical, and chromatographic methods are accompanied by seminars and numerous laboratory sessions.

Not less than $30 \%$ of the variable part of the educational program should be reserved for other special courses, depending on the choice of the division. Some examples of additional special courses offered at many universities are as follows:

- Kinetic, biochemical, and biological methods of analysis

- Mass spectrometry and chromatography-mass spectrometry

- Methods of local and surface analysis

- Chemical and biochemical sensors: theory and practice

- Radiochemical and nuclear analytical techniques

- Flow-injection and continuous-flow analysis

- Computerization, miniaturization, and automation of chemical analysis

- History and methodology of analytical chemistry

- Analytical control in industry, environmental monitoring, biotechnology, and clinical diagnostics

- Out-of-laboratory methods of analysis
- "Hyphenated" and hybrid methods of analysis

- Analytical laser spectroscopy

The choice of these courses is obviously governed by the scientific interests of the division, available instrumentation, and regional requirements. All universities are obliged to offer a large number of elective courses. Today, one of the trends is to offer special courses or even major courses in the standardization and certification of materials, foodstuff, oil, and other products.

During the seventh, eighth, and ninth semesters all specialist students have to conduct research in their chosen laboratory. At the end of each semester they have to pass a test by giving an oral presentation in a laboratory seminar on the results of their work.

The last semester (the tenth for specialist students and the eighth for bachelor students) is devoted to diploma work, which is a serious scientific investigation in one of the modern and promising fields of analytical chemistry for specialist students, and a rather short and concrete work for bachelor students.

The diploma (certificate) for specialist students graduating from classical universities shows two professions: not just "chemist-researcher" but also "teacher of chemistry", as the students have special lectures, seminars, tests, and examinations on education science and the methodology and practice of chemistry teaching. They even have a short practice in teaching chemistry in schools and assisting professors during the laboratory work of undergraduate students. So, our graduates have the right to work as school teachers as well. This new practice does not mean that there are no special teachertraining institutions (universities) in Russia. But the implementation of teaching disciplines into the curriculum of classical universities gives their graduates the possibility to work in secondary schools if they wish, without having to study at a teacher training college for 2 years.

With regard to the "quality" of the teaching staff who participate in teaching bachelor, specialist, and master students at the universities, 95\% of them have a Ph.D. degree, and many of them have a doctor of science degree. At the same time, Ph.D. students also participate in the education process, teaching undergraduate students in nonchemistry departments.

\section{Textbooks}

While studying, Russian students use textbooks preferably written by Russian authors [11-14]. Besides these, American and European textbooks translated into Russian (such as Fundamentals of Analytical Chemistry by D.A. Scoog and D.M. West, 1997; Analytical Chemistry by G.D. Christian, 2004; Analytical Chemistry edited by R. Kellner, J.-M. Mermet, M. Otto, and H.M. Widmer, 1998) 
are used $[16,17]$. Several new textbooks on analytical chemistry for bachelor courses and on various methods of analytical chemistry for master courses are being prepared for publication.

\section{Advantages and drawbacks of the reforms}

As every coin has two sides, the results of Russian higher education reforms also have positive and negative aspects. Indeed, graduate students have become more mobile (predominantly within Russia) and have the opportunity to change their major when going from one educational level to another, as well as the opportunity to be educated at a higher professional level. Prerequisites have been created to raise the intellectual level of applicants for higher degrees owing to an inflow of gifted bachelors from faraway universities in relatively small cities seeking a master degree from top-ranked universities in the Russian Federation and Europe. The possibilities for integration into the international educational system are becoming wider. Russian graduates have never had problems with mobility in selecting a university in European countries, the USA, and Canada for their further education.

However, according to the opinion of leading scientists and professors from the main Russian universities, the situation now in Russian higher education has serious drawbacks. A significant decrease in teaching the basics of analytical chemistry and the duration of research in bachelor courses (in comparison with specialist courses) has led to bachelors having employability problems. Graduates with a shortened basic education acquired through bachelor courses are less capable of creating and developing modern technology in various branches of industry, agriculture, etc. Bachelors' skills are limited, as they have only 6 credits for practical activity, whereas specialists have 39 credits. The qualification of bachelor was not included until now in the Labor Code. Employers at chemistry institutions, chemical companies, and industrial enterprises often do not know the status of bachelors, their abilities, and the appropriate salary level. When bachelors try to compete with specialists to find a job, they usually fail. If they finally find a job, they have fewer prospects for professional development. That is why many bachelors have to enter a master course to enhance their professional status. Many entrants to those universities that offer both bachelor and specialist courses prefer to enter the latter because in this case they have more possibilities to find a job after graduation - either in the research laboratories of scientific institutions or in analytical laboratories of industrial or equipment companies. Besides, specialists may continue studying for a Ph.D. degree after 5 years not 6 years of study, a duration which is an important factor for young people. Recently the Ministry of Labor of the Russian Federation confirmed the three levels of qualification - bachelor, specialist, and master-and in the future, employers will be expected to invite graduates and pay them according to these levels.

At the third Russian Congress on Analytical Sciences (October, 2017), it was stated that to widen the possibilities for bachelors to find a proper job after graduation, it would be more useful to train them as laboratory assistants capable of working in the sphere of material production (industrial scientific organizations or plant laboratories) or state and regional control (systems of environmental monitoring and sanitary control; laboratories monitoring the quality of food or oil products, pharmaceuticals, forensic laboratories, etc.).

In some cities there is a long-term strategic partnership in training professionally educated bachelors between industrial enterprises and technical universities. This makes it possible for employers to actively participate in developing the educational programs and training exclusive experts who have knowledge of a concrete enterprise, whereas for the university it is a chance to have a test site where it is possible to estimate students' skills in the course of training. Specialists in analytical laboratories of an enterprise participate in defining the topics for graduate research performed with modern expensive analytical equipment owned by the enterprise. The research is aimed at the development or modernization of analytical protocols for the analysis of industrial products, raw materials, or environmental samples. Such university-industry interaction results in each real student's theme becoming a complex multipurpose research, and the enterprise enrolls highly qualified specialists with the necessary profile. For example, analysis of the long-term cooperation between metallurgical enterprise Novolipetsk Steel and Lipetsk State Technical University revealed the following obvious benefits in realizing educational projects: increase of graduates' employment level; reduction of the adaptation period for young specialists at work; increase of the teaching staff's qualifications; modernization of material and technical facilities and use of modern analytical equipment in the educational process; and new opportunities to train highly qualified specialists in the context of their further postgraduate education.

The positive experience of the integrative cooperation of the technical universities is now used to establish ties with different enterprises in the regions that enroll specialists in analytical chemistry; in particular, laboratories of sanitary and veterinary services and enterprises in the food and pharmaceutical industries.

\section{Novel forms of teaching analytical chemistry}

As many credits are now allocated for special courses in analytical chemistry during master courses or during the fourth, 
fifth, and sixth years for MSU specialist students, the analytical chemistry divisions are trying to find and implement novel forms of teaching. For example, various novel forms of conducting seminars are actively being implemented in different universities, such as student discussions, analysis of problem situations, oral presentations on topics given earlier, teambuilding tasks, and use of active and interactive forms. Besides, at MSU, for example, numerous interdepartmental elective courses (not less than 4 credits) in different areas of science, not only in chemistry, are now mandatory for students of all years. For instance, students in the chemistry department can take a course in biology, psychology, medicine, philology, history, etc.

Every year, student scientific conferences are organized in many universities with the participation of students from all over the country. For example, students in the second to sixth years at MSU participate very actively in the annual scientific conference "Lomonosov" together with their colleagues from many other universities from different cities and present the results of their research conducted during their free time. Analogous student conferences are organized by the universities of St Petersburg, Tomsk, Ekaterinburg, and Bashkortostan, among others. This practice gives students the chance to obtain experience in effective poster and oral presentation design and delivery, and participation in scientific discussions [18].

To form closer contacts between universities and employers, $10 \%$ of teachers of master courses and $5 \%$ of teachers of bachelor courses should be from state and commercial companies according to the Ministry of Education and Science recommendations. New rules for graduate examinations and defense of the diploma thesis for specialists have been implemented in some universities, MSU in particular. Now the panel of state examination and diploma examiners should consist not only of university professors but should include 50\% representation by "potential employers' (academic institutions, industrial and equipment companies), who should participate in these examinations.

To improve their programs and plans, universities have agreements on cooperation and scientific contacts with state corporations and companies (such as UralChem, EuroChem, Lukoil, Rusnano, Rusatom, and the Russian Space Agency). The universities have to coordinate the development of competences and skills of their graduates with the professional qualification standards of different branches of manufacturing and innovative industries to widen their graduates' possibilities to find a good job.

One more novelty is the active introduction of distant online lectures (by use of telecommunication networks on a special website, learning management system) for teaching students and improving the qualifications of professors at those universities that do not have high-level specialists in some modern areas of analytical chemistry. Colleagues from other universities who have the necessary knowledge deliver these lectures.

\section{Recruiting schoolchildren to the universities}

As the Russian education reforms affected school education as well, universities pay great attention to training schoolchildren in chemistry and stimulating those with good knowledge to enter chemical departments of universities. Various types of "evening (or summer, winter) schools" in various fields of chemistry, and analytical chemistry in particular, and chemical olympiads of various levels are organized to help the winners enter universities more easily. Besides, many chemistry departments hold special chemistry classes in secondary schools and grammar schools, teaching children and recruiting them to the universities.

\section{Conclusion}

This overview is based on my oral presentation "Current state of Russian higher education: six years of reforms" in the session on education during the 19th Euroanalysis meeting in Stockholm, August 28 to September 1, 2017 (http:// euroanalysis2017.se), on my plenary presentation "The reforms of Russian higher education: advantages and drawbacks" at the third Russian Congress of Analytical Sciences (October, 2017), and the presentations of the representatives of different universities at the Symposium on Analytical Chemistry Teaching in the frame of that congress (http://analystscongress.ru). All the data on the situation in Russian universities presented in this article were obtained as a result of the survey of the universities performed last spring by the Commission on Analytical Chemistry Teaching of the Scientific Council on Analytical Chemistry of the Russian Academy of Sciences, which heads the activities of the united community of professors and teachers of analytical chemistry in Russia.

This commission controls all the mentioned processes taking place in reforming analytical chemistry teaching and the new programs, promotes cooperation between the analytical chemistry divisions of all the classical and technical universities in the country, organizes conferences on topical problems in analytical chemistry teaching every $2-3$ years, accumulates the experience of various universities in analytical chemistry teaching and spreads the necessary information among other universities, develops the recommendations related to the various aspects of teaching using its website, etc.

Now when Russian universities are at the beginning of the reforms, the role of the commission is especially great. We hope that the joint efforts of the community of professors and teachers of analytical chemistry in Russia will provide a 
successful solution to the problem on how to join the European Higher Education Area while not losing all the advantages of a traditional Russian education.

\section{References}

1. Salzer R. Changing careers in chemistry. Anal Bioanal Chem. 2012;402:25-8. https://doi.org/10.1007/s00216-011-5536-8.

2. Griffiths PR. Whither "quant"? An examination of the curriculum and testing methods for quantitative analysis courses taught in universities and colleges in the western USA. Anal Bioanal Chem. 2008;391:875-80. https://doi.org/10.1007/s00216-008-2080-2.

3. Shekhovtsova TN, Vershinin VI. What kind of professional training of analytical chemistry is required in classical universities? J Anal Chem. 2001;56(1):81-7.

4. Karayannis MI, Efsrathiou CE. Significant steps in the evolution of analytical chemistry - is the today's analytical chemistry only chemistry? Talanta. 2012;102:7-15. https://doi.org/10.1016/j. talanta.2012.06.003

5. Matilainen R, Koliseva A, Valto P, Jouni Välisaari J. Reconstruction of undergraduate analytical chemistry laboratory course. Anal Bioanal Chem. 2017;409:3-10. https://doi.org/10. 1007/s00216-016-9953-6.

6. Wenzel TJ. Active learning materials for equilibrium chemistry and separation science. Anal Bioanal Chem. 2011;400:637-40.

7. Zolotov YA. Some trends in modern analytical chemistry. J Chromatogr Sep Tech. 2017;8:355. https://doi.org/10.4172/21577064.1000355.

8. Cavinato AG. Challenges and successes in implementing active learning laboratory experiments for an undergraduate analytical chemistry course. Anal Bioanal Chem. 2017;409:1465-70. https://doi.org/10.1007/s00216-016-0092-x.

9. Salzer R. Master programs in analytical chemistry. Anal Bioanal Chem. 2009;394:649-53. https://doi.org/10.1007/s00216-0092755-3.

10. Stone DC. Should students be graded on accuracy and precision? Assessment practices in analytical chemical education. Anal Bioanal Chem. 2017;409:1719-24. https://doi.org/10.1007/ s00216-016-0109-5.
11. Zolotov YA, editor. Fundamentals of analytical chemistry (Osnovy analyticheskoy chimii). Moscow: Academia; 2014. (In Russian).

12. Zolotov YA, editor. Fundamentals of analytical chemistry. Practical instructions (Osnovy analyticheskoy chimii. Practicheskoe rukovodstvo). Moscow: Laboratorya Znanyi; 2017. (In Russian).

13. Moskvin LN, editor. Analytical chemistry (Analyticheskaya chimia). Moscow: Academia; 2010. (In Russian).

14. Ischenko AA, editor. Analytical chemistry and physicochemical methods of analysis. (Analyticheskaya chimia i physicochemicheskie methody analyza). Moscow: Academia; 2010. (In Russian).

15. Scoog DA, West DM. Osnovy analyticheskoi chimii. Moscow.: Mir; 1979.

16. Christian GD. Analytical chemistry (Analyticheskaya chimia). Moscow: BINOM Laboratorya Znanyi; 2009. (In Russian).

17. Kellner R, Mermet J-M, Otto M, Widmer HM, editors. Analytical chemistry. Problems and approaches (Analyticheskaya chimia. Problemy i podchody). Moscow: Mir; 2004. (In Russian).

18. Beuning PJ. Research skills and ethics: the 20-year evolution of a professional development graduate course. Anal Bioanal Chem. 2017;409:859-62. https://doi.org/10.1007/s00216-016-9989-7.

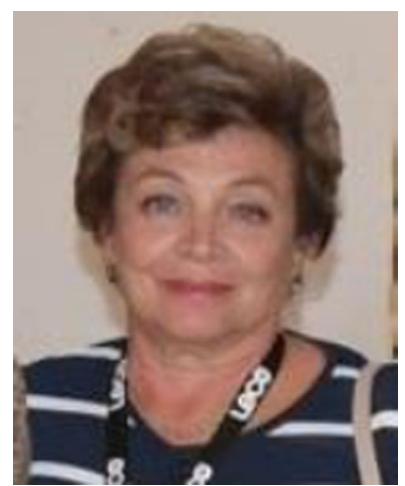

Tatiana N. Shekhovtsova received her Ph.D. (1974) and D.Sc. (1996) degrees in chemistry from M.V. Lomonosov Moscow State University (MSU). She is a full chair professor in analytical chemistry in the Department of Chemistry, MSU. She is also Head of the Commission on Teaching Analytical Chemistry in Russian Universities and Head of the Commission on Biochemical Methods of Analysis of the Scientific Council on Analytical Chemistry of the Russian Academy of Sciences. Her research interests include basic studies and applications of enzymatic methods of analysis. 